\title{
Bipolar Hemiarthroplasty as Coxofemoral Bypass Technique in Treating Unstable Pertrochanteric Comminuted Fracture of Elderly Patients
}

\author{
Neetin Pralhad Mahajan¹, Pramod K. Bagimani², Kartik Prashant Pande ${ }^{3}$, Ravi Rameshbhai Dadhaniya ${ }^{4}$ \\ 1, 2, 3, 4 Department of Orthopaedics, Grant Government Medical College and Sir JJ Group of Hospital, \\ Mumbai, Maharashtra, India.
}

\section{ABSTRACT}

\section{BACKGROUND}

Pertrochanteric fractures in the elderly are highly unstable and osteoporotic. Comminution of fragments and distraction fragments make union difficult owing to forces acting on the proximal hip joint. The internal fixation in these cases leads to prolonged bed rest and immobilization to prevent implant failure. The purpose of this study was to analyse the role of bipolar hemiarthroplasty in cases of unstable pertrochanteric femur fractures as bypassing forces transmission through the proximal femur.

\section{METHODS}

30 patients with pertrochanteric fractures were randomized and operated on as bipolar hemiarthroplasty using the indigenous bipolar prosthesis between July 2017 and July 2021. The inclusion criteria were patients more than 65 years of age, Type 4 intertrochanteric fracture (As per Evans classification) AO/ OTA type 31A2.3, 31A3.2, 31A3.3. Patients with polytrauma, compound injuries, pathological fractures and medically unfit patients were excluded from the study.

\section{RESULTS}

The mean age was $67 \pm 5$ years. The most common mechanism of injury was domestic fall comprising $80 \%$. The average duration of surgery from the time of injury was $3.5 \pm 1.5$ days. The average surgical duration was 85.5 mins. The average duration of stay in the hospital was $8.5 \pm 1.5$ days. Final results were calculated using the Harris Hip score with $33.3 \%$ cases as excellent, $56.6 \%$ cases as good and $10 \%$ cases had fair results respectively. Follow-up was done at 6 weeks, 3, 6, 12 and 24 months.

\section{CONCLUSIONS}

Bipolar hemiarthroplasty in pertrochanteric femur fractures has the advantage of stable adequate fixation with early return to activities of daily living, thus preventing serious life-threatening complications.

\section{KEY WORDS}

Intertrochanteric Fractures, Hemiarthroplasty, Femur, Harris Hip Score.
Corresponding Author: Dr. Kartik Prashant Pande, \#300, Resident Hostel, JJ Hospital, Byculla,

Mumbai-400008, Maharashtra, India. E-mail: kartik.pande0393@gmail.com

DOI: $10.14260 / j e m d s / 2021 / 746$

How to Cite This Article:

Mahajan NP, Bagimani PK, Pande KP, et al. Bipolar hemiarthroplasty as coxofemoral bypass technique in treating unstable pertrochanteric comminuted fracture of elderly patients. J Evolution Med Dent Sci 2021;10(43):3683-3688, $10.14260 /$ jemds/2021/746 DOI:

Submission 05-09-2021,

Peer Review 15-10-2021,

Acceptance 21-10-2021,

Published 25-10-2021.

Copyright (c) 2021 Neetin Pralhad Mahajan et al. This is an open access article distributed under Creative Commons Attribution License [Attribution 4.0 International (CC BY 4.0)] 


\section{BACKGROUND}

Pertrochanteric region of the proximal femur in the elderly sustains osteoporotic multifragmentary fracture patterns following low-grade domestic falls and associated medical diseases. They are difficult to get in contact with each other owing to available methods of osteosynthesis. Pertrochanteric femur fractures in the elderly are highly unstable and difficult to treat as the bones are osteoporotic. ${ }^{1}$ The internal fixation in these cases leads to prolonged bed rest and immobilization, to prevent the implant failure. ${ }^{2}$

Among the intertrochanteric fractures, the unstable (Type 4) fractures are more difficult to treat as well as prognosis. Osteoporosis associated with a difficult reduction in such types of fractures dictates the final outcome. ${ }^{3}$ The commonly encountered fractures in orthopaedics are pertrochanteric fractures. $^{3} \quad$ Pertrochanteric fractures with severe displacement or comminution are common in elderly patients with poor bone quality. ${ }^{4}$ Complications associated with the standard methods of internal fixation devices are high as Baumgartner et al. found $20 \%$ of implant failure in trochanteric fractures. ${ }^{5}$

Problems that are associated with the internal fixation of unstable pertrochanteric fractures in elderly patients with osteoporotic bones are excessive collapse, loss of fixation, and cut-out of the lag screw, which result in poor function.

For unstable osteoporotic trochanteric fractures, hemiarthroplasty using cone prosthesis can transfer the axial load from the hip to the middle femur, which leads to early postoperative weight-bearing.

For early postoperative weight-bearing, rapid rehabilitation and to avoid the excessive collapse at the fracture site, some surgeons have recommended replacements for the treatment of unstable pertrochanteric fractures.

The purpose of this prospective study was to evaluate the functional and clinical outcomes of bipolar hemiarthroplasty as a primary treatment for unstable pertrochanteric femur fractures in elderly patients.

\section{METHODS}

This study is a retrospective study where 30 cases of unstable comminuted pertrochanteric fractures from the inpatients with bipolar hemiarthroplasty were studied over between July 2017 and July 2021 at a tertiary care hospital in Mumbai. The inclusion criteria were patients more than 65 years of age, unstable type 4 intertrochanteric fracture as per Evans classification, ${ }^{6}$ AO/ OTA type 31A2.3, 31A3.2, 31A3.3. Patients with ambulatory status before the fracture were selected for study to know the recovery of pre-injury functions. Patients with polytrauma, medically unfit, patients with cardio-respiratory distress and allergic to cement were excluded from the study.

Pre-operative data included: Age, sex, side, fracture type and mode of injury. Post-operative data included time to full weight bearing, average hospital stay and complications. The patients provided written informed consents.
All surgical procedures were performed by the same surgical team as soon as the condition of the patients was stabilized, usually within 3-4 days after their admissions.

The operation was performed by using the posterolateral approach, with the patients in the lateral decubitus position. The femoral head and neck were removed. Meticulous care was taken to preserve the integrity of the greater trochanter, abductor muscles, and all the vascularized bone fragments. The femoral medullary canal was then reamed to the appropriate stem size and diameter. Trial reductions were performed to determine the exact length that would provide the desired tension and tissue balancing of the abductor muscles and an equal leg length. Careful restoration of neck length, offset and version to maximize the stability of the hip joint, was also performed during the trial. Both cemented femoral stem prostheses were used (Fig. 2). The lesser trochanter was not removed. Loose osteoporotic fragments were removed. The greater trochanter was reduced and stabilized by using the tension band by wiring technique after hip reduction or it was just sutured near the prosthesis (Fig. 3 ). The gluteus medius muscle and vastus lateralis were sutured to their anatomical locations by using anchor sutures, if necessary. Fascia lata was tightly closed over a suction drain. Post-operative radiographs were obtained [Fig. 5 \& 6]

Patients were ambulated full weight bearing on the first post-operative day. (Fig. 4) Complications such as dislocation, infection, fat embolism, bedsore and hyponatremia were monitored. The sutures were removed on day 12 and the patients were discharged.

They were followed up at 6 weeks, 3 months, 6 months and 12 months (Fig. 7). Clinical evaluation was done according to Harris Hip score. (Table -1) Anteroposterior radiographs of the hip were analyzed at each follow up to note any evidence of loosening, shortening and resorption.

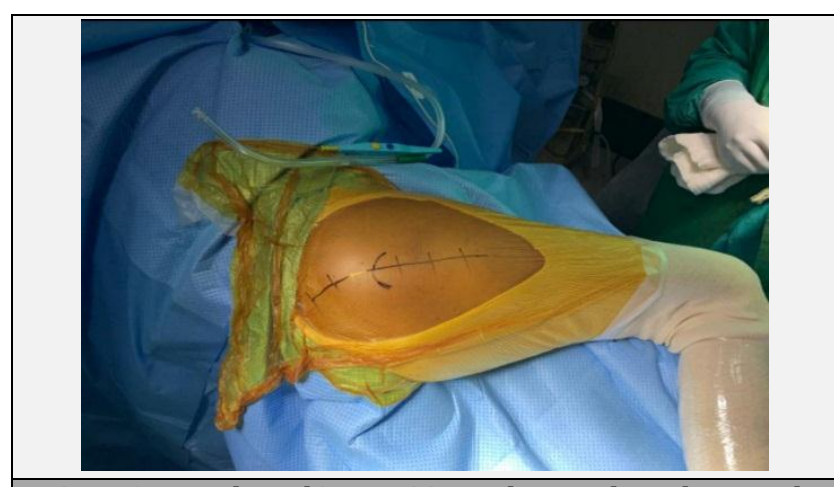

Figure 1. Lateral Decubitus Position and Posterolateral Approach

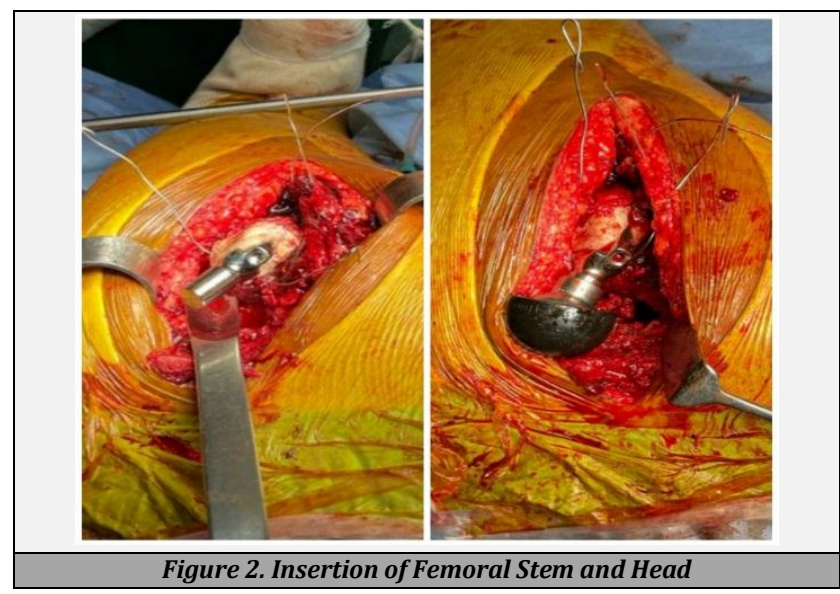




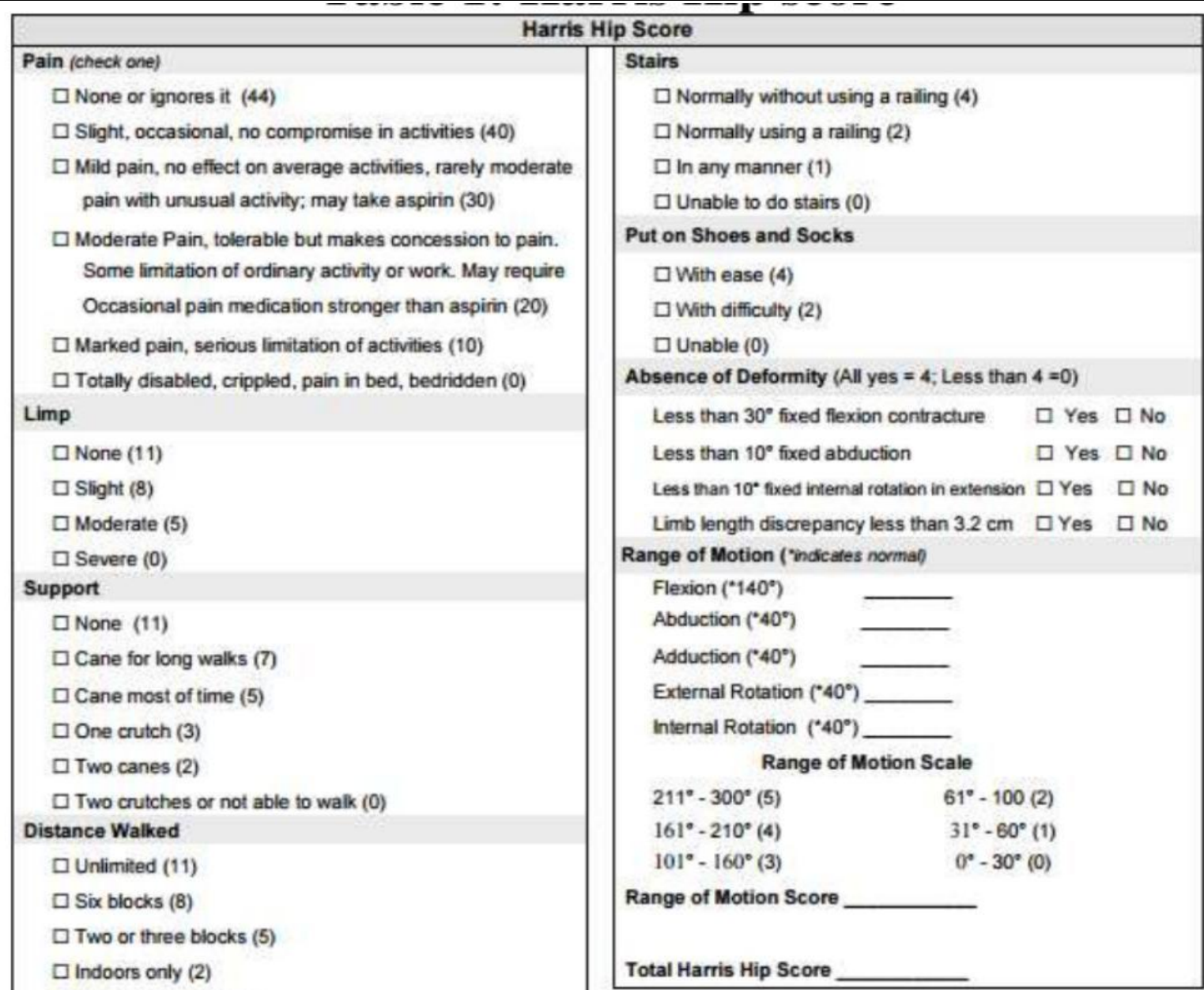

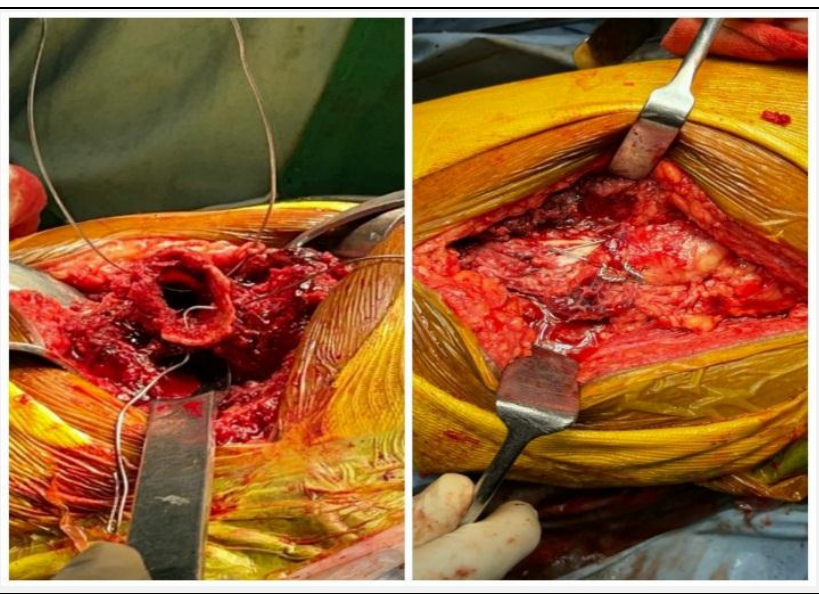

Figure 3. TBW and Cerclage Technique Used for GT Fixation

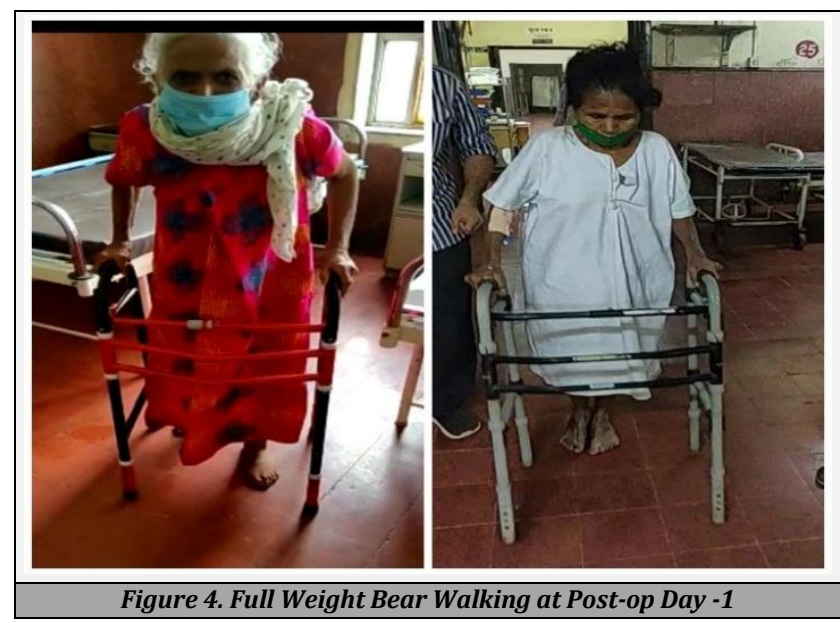



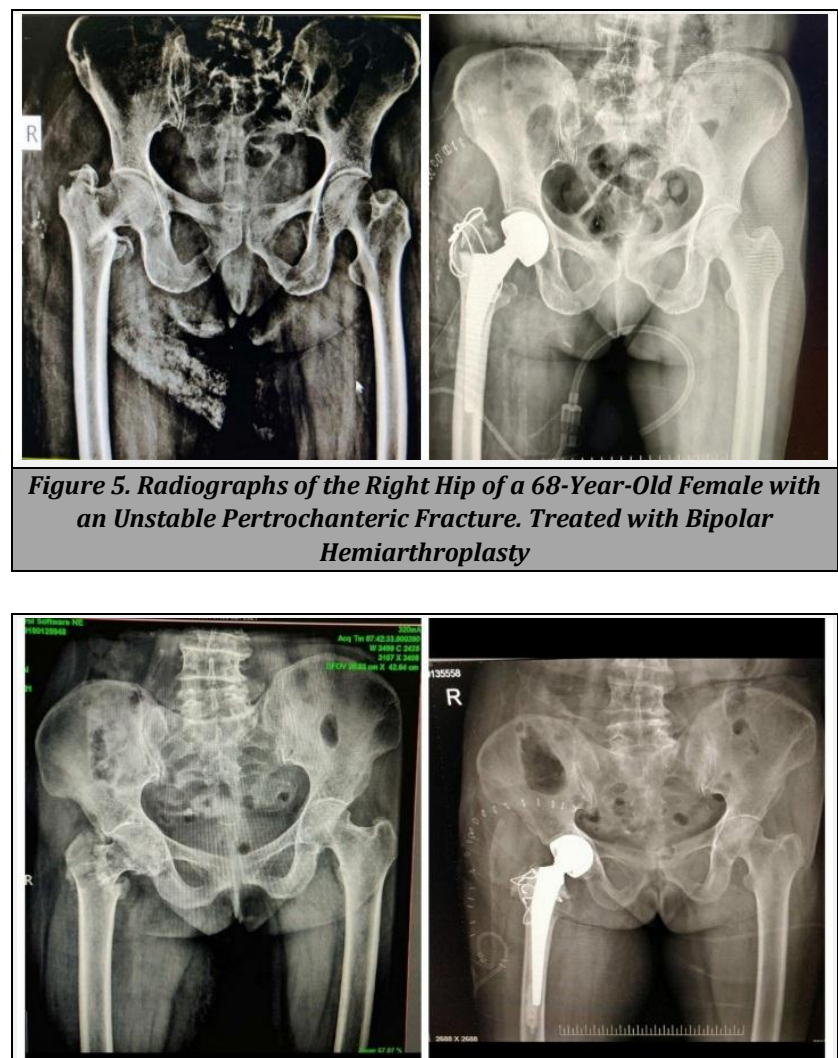

Figure 6. Radiographs of the Right Hip of a 74-Year-Old Female with Unstable Pertrochanteric Fracture. Treated with Bipolar Hemiarthroplasty

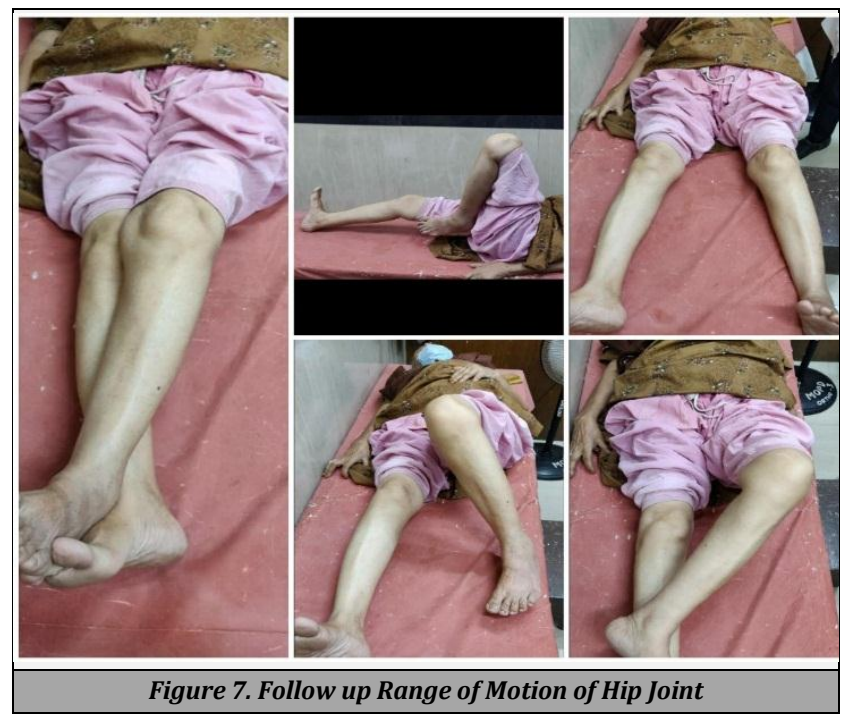

\section{RESULTS}

The mean age observed was $75 \pm 5$ years, with $60 \%$ of the cases in the age group between 70 - 80 years. Seventy percent of the cases were females. The right side was predominantly involved in the majority of the cases. The most common mode of injury encountered was a domestic fall comprising of 24 cases $(80 \%)$. The average duration of surgery from the time of injury was $3.5 \pm 1.5$ days.

The average operating time was 115.5 mins with $230 \mathrm{ml}$ of blood loss intra-operatively. Intra-operative blood was measured with the help of blood collected in the mops used during the surgery. The average duration of stay in the hospital was $8.5 \pm 1.5$ days.

\begin{tabular}{|ccc|}
\hline Degree of Placement of a Prosthesis & No. of Patients & Percentage \\
5-10 retroversion & 0 & 0 \\
Neutral & 1 & 3.3 \\
5-degree anteversion & 1 & 3.3 \\
10-degree anteversion & 2 & 6.6 \\
15-degree anteversion & 22 & 73.3 \\
20-degree anteversion & 3 & 9.9 \\
> 20-degree anteversion & 1 & 3.3 \\
\hline Placement of Prosthesis \\
\hline
\end{tabular}

\begin{tabular}{|ccc|}
\hline Discrepancy in cm & No. of Patients & Percentage \\
\hline 0.5 cm shortening & 5 & 16.6 \\
1 cm shortening & 2 & 6.6 \\
1.5 cm shortening & 1 & 3.3 \\
2 cm shortening & 0 & 0 \\
No discrepancy & 20 & 66.6 \\
0.5 cm lengthening & 1 & 3.3 \\
1 cm lengthening & 1 & 3.3 \\
\hline & Limb Length Discrepancy \\
\hline
\end{tabular}

\section{Dislocation}

- 1 case-needed closed reduction.

- 1 case- needed open reduction and capsular repair.

\section{Infection}

- 2 cases, 1 case needed single debridement.

- 1 case needed 2-time debridement's, antibiotics for 3 weeks.

- Bedsores- none.

\section{Fat embolism}

1 case manifested with stroke on MRI.

\section{Hyponatremia}

3-4 cases of hyponatremia and recovered.

\section{Sciatic nerve palsy}

None.

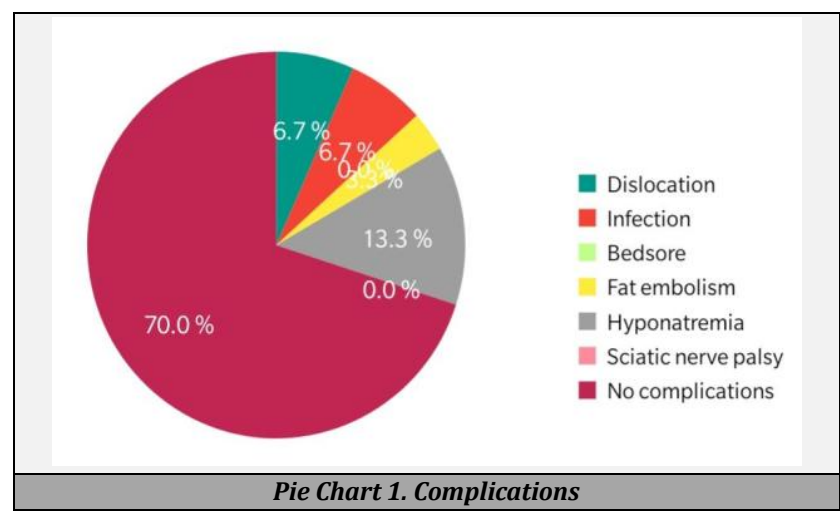

Final results were calculated using the Harris Hip score (Table 1). 10 (33.33\%) patients had excellent, 17 (56.66\%) had good, $3(10 \%)$ had fair and $0(0 \%)$ patients had poor results respectively (Table 2 ). Regular follow-up was done at $1,3,6,12$ and 24 months.

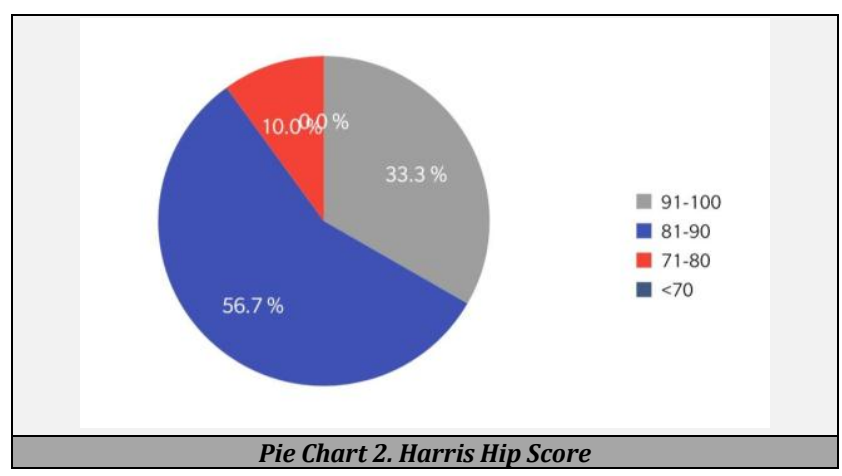




\begin{tabular}{|ccc|}
\hline Score & No. of Cases & Percentage (\%) \\
\hline $91-100$ (excellent) & 10 & 33.3 \\
$81-90$ (good) & 17 & 56.66 \\
$71-80$ (fair) & 03 & 10 \\
$<70$ ( poor) & 00 & 00 \\
Total & 30 & 100 \\
\hline Table 2. Results as per Harris Hip Scoring (Pie Chart-4) \\
\hline
\end{tabular}

\section{DISCUSSION}

There is still no evidence regarding the best treatment method for unstable pertrochanteric fractures and fixation materials. ${ }^{7}$ Recently, the focus of controversy regarding the optimal treatment method for elderly patients with intertrochanteric fractures has been on how to lower postoperative complications and mortality rates. Although the first choice of treatment for the unstable intertrochanteric femur fractures is internal fixation, bipolar hemiarthroplasty will provide stability and early mobilization which is most important for the elderly patients, that it might decrease the rate of mortality and morbidity. ${ }^{8}$

In elderly patients due to osteoporosis in unstable fracture, the other methods like dynamic hip screw (DHS) will not allow early weight-bearing and a higher rate of failure 5 to $12 \%$ has been noted. ${ }^{9}$ In DHS, the plate is fixed to the lateral wall, in case of medial cortical defects that may cause complications, including the screw cutting the femoral head, internal displacement or plate-side screw extrusion and non-union. In the past, Haentjens et al. investigated the clinical outcomes of internal fixation compared with bipolar hemiarthroplasty and reported $75 \%$ satisfactory results and fewer postoperative complications in the arthroplasty group. ${ }^{10}$

The earliest comparison of internal fixation and hemiarthroplasty was done by Haentjens et al. showing a significant reduction in the incidence of pneumonia and pressure sores in those undergoing prosthetic replacement. For these reasons, some surgeons favour the use of bipolar hemiarthroplasty, which will allow early weight-bearing with a lesser risk of mechanical problems. Liang et al. concluded in their study that hemiprosthesis is an effective modality that can decrease the morbidity, mortality and the cumulative financial burden of the patient family. ${ }^{11}$

Bipolar hemiarthroplasty has fewer complications than unipolar implants such as dislocation, loosening and protrusion because this prosthesis has dual bearing surfaces, so sharing the motion at two surfaces reduces the complications. ${ }^{12}$ In cases where comminuted fractures of the greater trochanter are accompanied by a reverse oblique intertrochanteric femoral fracture, anatomical reduction and rigid fixation of bone fragments are significant due to consequences including hip pain and changes in the lever arm covering the centre of the hip throughout to the abductor muscle's point of action, potentially resulting in dislocation of an artificial joint due to weakened abductor muscles. ${ }^{13}$

In cemented bipolar hemiarthroplasty as we fix the femoral stem into the shaft of the femur, it will transmit the stress of weight-bearing directly to femur diaphysis bypassing the posteromedial area of the proximal femur. ${ }^{14}$ Early full weight-bearing in bipolar hemiarthroplasty will reduce the complications. ${ }^{14}$

\section{CONCLUSIONS}

Pertrochanteric fractures of the femur are very common among old age patients, females being more commonly affected. The most common mode of injury is domestic fall. According to our results, we believe that bipolar hemiarthroplasty in case of unstable pertrochanteric femur fractures in freely mobile elderly patients above sixty years of age gave early mobilization, early return to pre-injury level, superior quality of life. Postoperative early full weightbearing after hemiarthroplasty avoids long-term immobilization, rehabilitation, deformities and need for revision surgeries.

Data sharing statement provided by the authors is available with the full text of this article at jemds.com.

Financial or other competing interests: None.

Disclosure forms provided by the authors are available with the full text of this article at jemds.com.

\section{REFERENCES}

[1] Kiran Kumar GN, Meena S, Kumar V, et al. Bipolar hemiarthroplasty in unstable intertrochanteric fractures in elderly: a prospective study. J Clin Diagn Res 2013;7(8):1669-71.

[2] Gadre N, Kalambe HV, Das S. Cemented bipolar hemiarthroplasty in the management of comminuted intertrochanteric fracture of femur in elderly. National Journal of Clinical Orthopaedics 2018;2(1):1-5.

[3] Naik LG, Badgire KS, Sharma JM, et al. Treatment of unstable intertrochanteric fractures with cemented bipolar prosthesis-a prospective study. Indian J Orthop Surg. 2017;3(1):27-30.

[4] Choy WS, Ahn JH, Ko JH, et al. Cementless bipolar hemiarthroplasty for unstable intertrochanteric fractures in elderly patients. Clin Orthop Surg 2010;2(4):221-6.

[5] Pradeep C, Anuj A, Abhishek G. Treatment of comminuted unstable intertrochanteric fracture in elderly patients with cemented bipolar prosthesis. Indian J Orthop Surg 2015;1(4):255-60.

[6] Jensen JS. Classification of trochanteric fractures. Acta Orthop Scand 1980;51(5):803-10.

[7] Celiktas M, Togrul E, Kose O. Calcar preservation arthroplasty for unstable intertrochanteric femoral fractures in elderly. Clin Orthop Surg 2015;7(4):436-42.

[8] Göçer H, Coşkun S, Karaismailoğlu N. Comparison of treatment of unstable intertrochanteric fracture with different arthroplasty methods. Niger Med J 2016;57(2):81-5.

[9] Rodop O, Kiral A, Kaplan H, et al. Primary bipolar hemiprosthesis for unstable intertrochanteric fractures. Int Orthop 2002;26(4):233-7.

[10] Haentjens P, Casteleyn PP, De Boeck H, et al. Treatment of unstable intertrochanteric and subtrochanteric fractures in elderly patients. Primary bipolar arthroplasty compared with internal fixation. J Bone Joint Surg Am 1989;71(8):1214-25. 
[11] Stern MB, Goldstein TB. The use of the leinbach prosthesis in intertrochanteric fractures of the hip. Clin Orthop Relat Res 1977;128:325-31.

[12] Patil V, Nandi SS, Naik S, et al. Functional outcome of unstable comminuted intertrochanteric fractures in elderly treated with primary bipolar hemiarthroplasty. Int J Orthop Sci 2019;5(1):59-62.
[13] Hersh CK, Williams RP, Trick LW, et al. Comparison of the mechanical performance of Trochanteric fixation devices. Clin Orthop Relat Res 1996;(329):317-25.

[14] Sinno K, Sakr M, Girard J, et al. The effectiveness of primary bipolar arthroplasty in treatment of unstable intertrochanteric fractures in elderly patients. $\mathrm{N} \mathrm{Am} \mathrm{J}$ Med Sci 2010;2(12):561-8. 